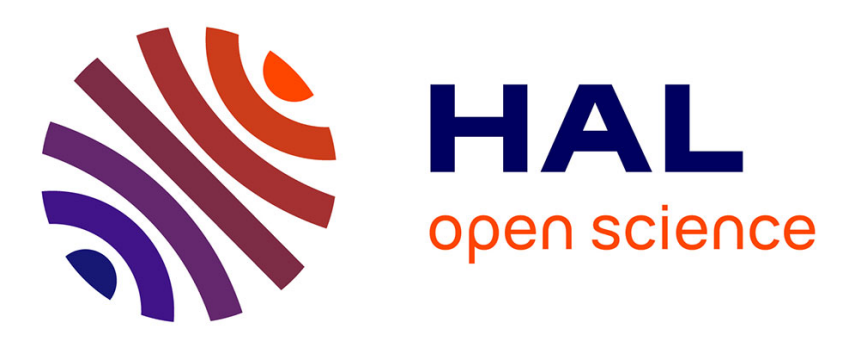

\title{
An IoT-based scheme for real time indoor personal exposure assessment
}

\author{
Houssem Eddine Fathallah, Vincent Lecuire, Eric Rondeau, Stéphane Le Calvé
}

\section{To cite this version:}

Houssem Eddine Fathallah, Vincent Lecuire, Eric Rondeau, Stéphane Le Calvé. An IoT-based scheme for real time indoor personal exposure assessment. 13th Annual IEEE Consumer Communications \& Networking Conference, CCNC 2016, Jan 2016, Las Vegas, United States. hal-01276928

\section{HAL Id: hal-01276928 \\ https://hal.science/hal-01276928}

Submitted on 21 Feb 2016

HAL is a multi-disciplinary open access archive for the deposit and dissemination of scientific research documents, whether they are published or not. The documents may come from teaching and research institutions in France or abroad, or from public or private research centers.
L'archive ouverte pluridisciplinaire $\mathbf{H A L}$, est destinée au dépôt et à la diffusion de documents scientifiques de niveau recherche, publiés ou non, émanant des établissements d'enseignement et de recherche français ou étrangers, des laboratoires publics ou privés. 


\title{
An IoT-based Scheme for Real Time Indoor Personal Exposure Assessment
}

\author{
Houssem Eddine Fathallah ${ }^{1,2}$, Vincent Lecuire ${ }^{1}$, Eric Rondeau ${ }^{1}$, Stéphane Le Calvé ${ }^{2}$ \\ ${ }^{1}$ CRAN UMR 7039, University of Lorraine, Nancy, France \\ ${ }^{2}$ ICPEES UMR 7515, University of Strasbourg, Strasbourg, France \\ Email: \{Houssem-eddine.fathallah, Vincent.lecuire, Eric.rondeau\}@univ-lorraine.fr, slecalve@unistra.fr
}

\begin{abstract}
Air pollution is an important environmental issue that has a direct effect on human health. In this paper the development of an Internet of Things-based system for real time indoor personal exposure monitoring is described. The system was tested for real time personal exposure assessment to formaldehyde and $\mathrm{CO}_{2}$ air pollutants. It provides accurate and real time personal exposure assessment. The real time and continuous monitoring capability makes it possible to better predict worker health risks and protect them from occupational overexposure to air pollution.
\end{abstract}

Keywords-component; Air quality; sensor networks; Internet of Things; personal exposure; real time monitoring.

\section{INTRODUCTION}

The human health consequences of air pollution are considerable. The world health organization (WHO) estimates that 800000 people per year die from the effects of air pollution [1]. In addition to posing a serious public health problem, poor indoor air quality impacts worker productivity. Two fundamental information are necessary to estimate personal exposure; the concentration of pollutant in different environments and individual time activity.

Last, recent development in communication and information technology allows personal exposure monitors to be ubiquitous and part of everyday activities without significantly impact personal daily function [2,3]. The Internet of Things (IoT) can be represented as a main enabling factor of promising paradigm for integration of several technologies for communication solution. IoT have emerged to be attractive in many applications such as, health care, target tracking and surveillance. This paper proposes the implementation of an IoT-based system for real time indoor personal exposure monitoring using multi-pollutant sensors nodes to measure air pollutants concentrations in different indoor microenvironments and wearable tags for real time indoor personal tracking.

\section{REAL TIME PERSONAL EXPOSURE MONITORING MODEL}

The proposed model estimates personal exposures by combining the information on the measured concentration of pollutants, the movements of a worker in various microenvironments and the time duration a worker spent in each microenvironment. In order to protect the occupational safety and health, Time-Weighted Average Individual Exposure $\mathrm{E}_{\mathrm{TWAi}}$ (Represents the allowable average individual air pollution exposure for a given period of time in relation to guidelines values duration) is updated periodically and compared with the $\mathrm{E}_{\text {TWAi Limit }}$ based on guidelines values and country regulations. In case of exceeding individual exposure limits alert management unit triggers the appropriate action (warning, ventilation, ask worker to take a break time etc...) to ensure personal health and risk prevention. An overview of real time personal exposure monitoring model is shown in Figure 1 where $\mathrm{C}_{\mathrm{MEj}}$ is air pollutant concentration in microenvironment $\mathrm{j}$ and $\mathrm{Ej}$ is individual exposure to air pollutant in microenvironment $\mathrm{j}$.

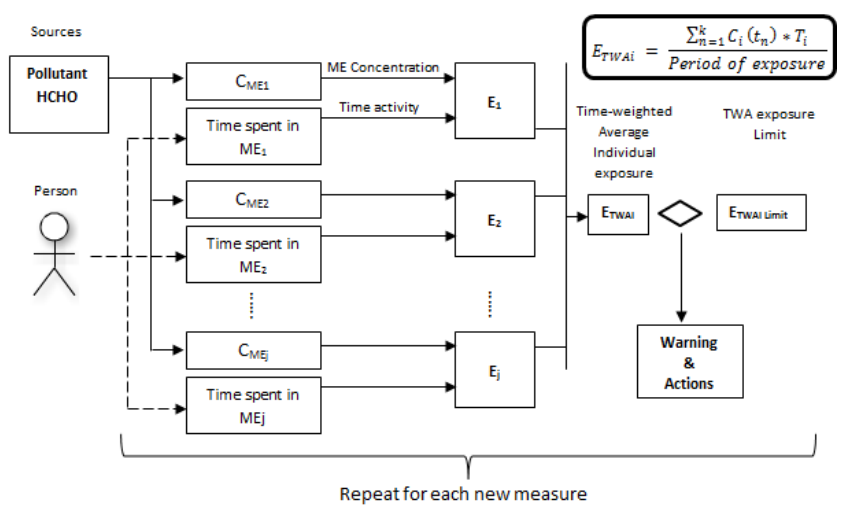

Fig. 1 Conceptual model for real time personal exposure monitoring

\section{SySTEM DESIGN AND EVALUATION}

\section{A. System architecture}

The architecture of an IoT-based system for real time indoor personal exposure monitoring is shown in Figure 2. Pollutants concentrations and real time personal coordinates data are remotely collected in a data center in which data are processed and made available to users. IoT is implemented as a network of interconnected "things" (Tags and multipollutant sensors nodes), each of which can be addressed using unique id and communicates based on standard communication protocols. 


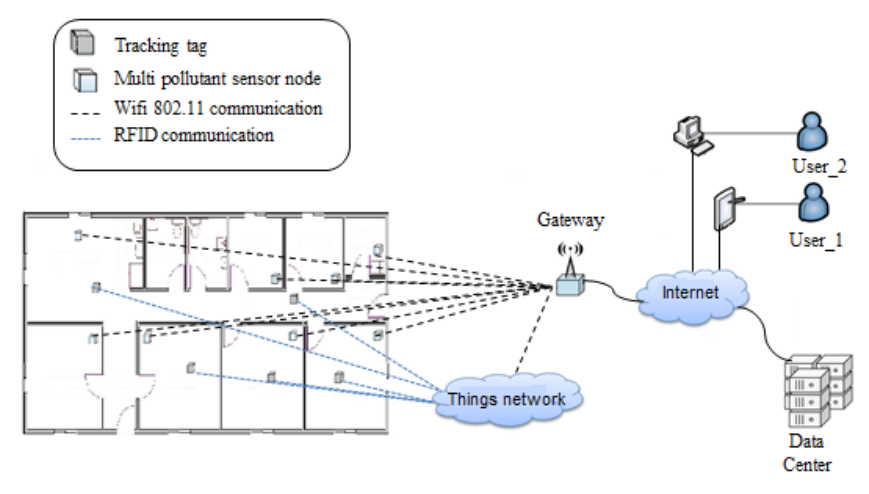

Fig. 2: System architecture

1) Multi-pollutant sensor node: sends periodically and wirelessly a message $<$ Node_Id, $T, \mathrm{H}, \mathrm{C}_{\mathrm{CO} 2}, \mathrm{C}_{\mathrm{HCHO}}$, Date, Time $>$ which contains the node identifier, pollutants concentrations and the measured date and time through the gateway to a central storage system in which data are processed.

2) Indoor positioning system: Each employee wears a tag with a unique Id. The tag sends periodically a message contains its Id and the location_Id provides by the zone locator $<$ Tag_Id, Location_Id $>$ through the gateway to a central system.

3) Data Center: central system: The central system is a back-end server that stores gathered data and provides those data for several services. Figure 3 shows the flowchart of the algorithm. In the first case, the process detects all workers locations $<$ Tag_Id, Location_Id $>$ and combines location data with the newest air pollutants concentrations. Then, the process updates each individual air pollutant concentration $\mathrm{C}_{\mathrm{i}}\left(\mathrm{t}_{\mathrm{n}}\right)$ with the new received air pollutant concentration $\mathrm{C}_{\mathrm{j}}\left(\mathrm{t}_{\mathrm{n}}\right)$ where $\mathrm{j}$ is the microenvironment $\mathrm{j}$ where participant is located. In this case the time spent in the microenvironment is $T_{i}=t_{m}-t_{\text {last }}$ where $t_{m}$ is the new air quality measurement time and $t_{\text {last }}$ is the last event trigger time.

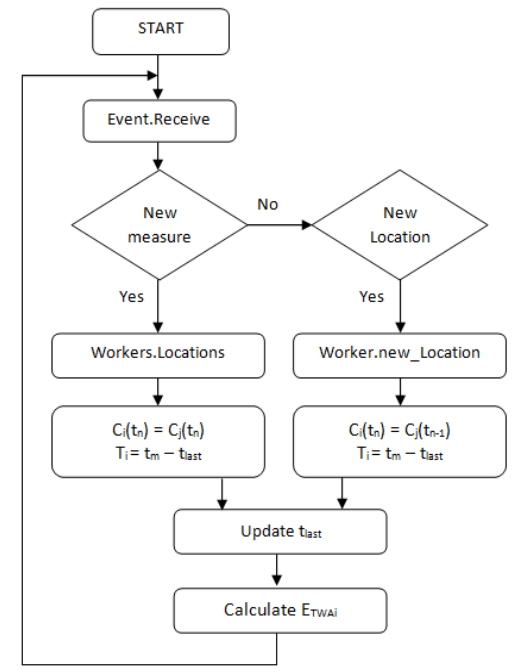

Fig. 3: flowchart of real time individual exposure assesment process
When a new worker location is received, the process updates the individual air pollutants concentrations $\mathrm{C}_{\mathrm{i}}\left(\mathrm{t}_{\mathrm{n}}\right)$ with the last received air pollutants concentrations $\mathrm{C}_{\mathrm{j}}\left(\mathrm{t}_{\mathrm{n}-1}\right)$. In this case, the time spent in the microenvironment is $T_{i}=t_{m o}-t_{\text {last. }}$. Finally the process updates $t_{\text {last }}$ and calculates the time-weighted average individual exposure ETWAi for each worker.

\section{B. Results and discussion}

We demonstrated that the IoT-based real time indoor personal exposure monitoring could provide effective monitoring of personal air pollution exposure at these sites. As an example, Figure 4 shows the real time personal exposure levels and $\mathrm{E}_{\mathrm{TWAi}}$ (with 30 min averaging time) to formaldehyde and $\mathrm{CO}_{2}$. The levels of personal formaldehyde and $\mathrm{CO}_{2}$ exposure increase sharply every time when the worker entered the copy room. The real-time monitoring capability of the IoT-based personal exposure monitor also revealed interesting details of air pollutant exposure.

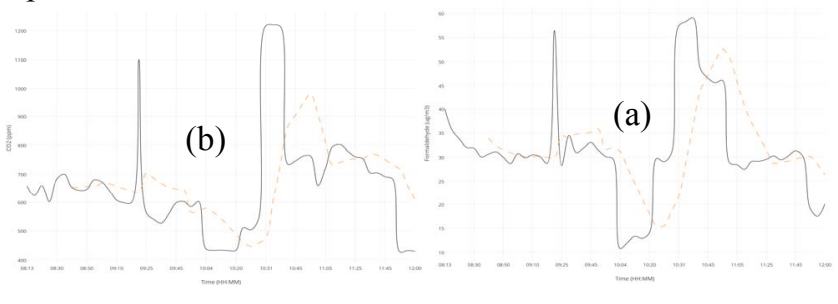

Fig.4 : Personal exposure levels and $\mathrm{E}_{\mathrm{TWAi}}$ to (a) formaldehyde and (b) $\mathrm{CO}_{2}$

\section{CONCLUSION}

The development of an IoT-based real time indoor personal exposure monitoring for real time occupational health and safety monitoring will help to be able to see high level worker exposure and their relation to specific microenvironments, sources and work tasks. This novel indoor monitoring scheme allows real time analysis of occupational air quality problems and making decision and action with regard to pollutants concentrations control policies and worker health protection. This approach can be extended to other type of pollution monitoring such as noise pollution.

\section{ACKNOWLEDGMENT}

This research is a part of CAPFEIN project funded by the French National Research Agency (ANR-11-ECOT-013).

\section{REFERENCES}

[1] WHO the World Health Report - Reducing Risks, Promoting Healthy Life, 2000.

[2] Negi I, Tsow F, Tanwar K, et al.ovel monitor paradigm for real-time exposure assessment Journal of Exposure Science and Environmental Epidemiology, 2011, 21, pp. 419-426

[3] Brown, K. et al. Reading Chemical Exposure Assessment Method with Real Time Location System, DREAM-RTLS, Cincinnati, ISES 2014. 